\title{
Pengaruh Geometri dan Kuat Medan Permanen dari Magnet Permanen NdFeB Terhadap Output Generator Fluks Aksial
}

\author{
Silviana Simbolon ${ }^{1,2, a)}$, Anggit Pringo Tetuko ${ }^{1,2,4}$, Candra Kurniawan ${ }^{2}$, \\ Krista Sebayang ${ }^{3}$, dan Perdamean Sebayang ${ }^{1,2}$ \\ ${ }^{1}$ Teknik Mesin, Universitas Pamulang, Jl. Surya Kencana No 1, Tangerang Selatan, 15417 \\ ${ }^{2}$ Pusat penelitian Fisika LIPI, Kawasan Puspiptek Serpong, Tangerang Selatan, 15314 \\ ${ }^{3}$ Fisika, Universitas Sumatera, Jl. Bioteknologi No 1, Medan, 20155 \\ ${ }^{4}$ RMIT University, 24 La Trobe St, Melbourne VIC, Australia, 3000 \\ Email: ${ }^{a)}$ simbolonsilvi@gmail.com
}

Masuk:2 Mei $2017 \quad$ Direvisi : 23 Mei $2017 \quad$ Disetujui : 6 Juni 2017

\begin{abstract}
Abstrak: Pada penelitian ini, telah dilakukan investigasi pengaruh bentuk geometri dan magnetik flux density terhadap output tegangan dari generator axial flux magnet permanen. Model dari generator axial didesain menggunakan sofware 3D Studio Max dan visual basic net express. Pada simulasi dan eksperimen digunakan magnet permanen $\mathrm{NdFeB}$ yang dibentuk circular dan rectangular dengan variasi magnetik flux density 0,$5 ; 0,8 ; 1,1 ; 1,3$ Tesla pada kecepatan rotasi sekitar 260 - 540 rpm. Dari hasil simulasi dan eksperimen ditunjukkan bahwa geometri magnet permanen sangat mempengaruhi dalam menghasilkan magnetik flux density maksimum. Hasil ini juga menunjukkan adanya korelasi antara output tegangan maksimum dengan magnetik fluk density maksimum. Semakin besar magnetik fluk density dan kecepatan rotor putar (rotasi) akan menghasilkan output tegangan yang semakin besar.
\end{abstract}

Kata kunci: generator, magnetic flux density, rotasi, voltage

\begin{abstract}
In this paper, the influence of geometric shapes and magnetic flux density on the maximum Voltage $\left(E_{\max }\right)$ of the axial flux permanent magnet generator has been investigated. Modeling of axial flux permanent magnet generator was designed using 3D Studio Max and visual basic net express software. The simulation and experimentally were performed by using NdFeB permanent magnet in the form of rectangular and circular shape with various Magnetic Flux Densities as 0.5, $0.8,1.1$, and 1.3 Tesla at the rotation speed around 260-540 rpm. The obtained results both from simulation and experiment show that the magnetic geometry, in this case the cross-section A, is directly proportional to the maximum magnetic flux, $\left(\Phi_{\max }\right)$. The results also showed that there was a correlation between the maximum Voltage $\left(E_{\max }\right)$ and the maximum magnetic flux, $\left(\left(\Phi_{\max }\right)\right.$. The increasing of magnetic flux density and rotor rotation increases the output voltage.
\end{abstract}

Keywords: generator, magnetic flux density, rotation, voltage

\section{PENDAHULUAN}

Pembangkit energi tenaga listrik berbasis mikroelektromekanik Sistem [MEMS] teknologi telah teliti secara ekstensif selama beberapa tahun terakhir. Sebagian besar penelitian dilakukan menggunakan prinsip damper winding, dimana damper adalah transduser yang mengubah energi mekanik menjadi listrik energi. Perangkat jenis ini telah dikembangkan berdasarkan Elektrostatik [1], elektromagnetik [2], [3], dan piezoelektrik [4].Generator magnet permanen (PM) dapat digunakan untuk konversi Energi mekanis rotasi menjadi energi listrik pada berbagai aplikasi dibandingkan dengan jenis mesin magnet lainnya, PM mesin memiliki beberapa keunggulan untuk beberapa aplikasi seperti interaksi magnetik dapat dibentuk sesuai ukuran mesin, sangat murah pembiayaan jika dibentuk dalam skala kecil dan memiliki geometri planar yang sangat konventional untuk MEMS. Untuk alat berbasis magnet permanen biasanya menggunakan magnet tanah jarang karena memiliki 
energy produk yang tinggi sebagai mekanikal elektro maksimum dan magnet $\mathrm{NdFeB}$ merupakan magnet dengan energy produk tertinggi [5-8].

Beberapa alat PM dalam skala mikro telah diteliti sebelumnya, semua menggunakan pendekatan kontruksi yang berbeda. Penelitian tentang self contained driven yang menggunakan magnet $\mathrm{NdFeB}$ telah memproduksi $1,1 \mathrm{~mW}$ dengan $30 \mathrm{krpm}$ dengan diameter 7,5 mm SU-8 rotor [9]. Group lainnya melaporkan telah berhasil mencapai $14,6 \mathrm{~mW}$ pada pada $58 \mathrm{krpm}$ menggunakan diameter $8 \mathrm{~mm}$ pada rotor NdFeB. D.P.Arnold membuat sebuah generator berbasis PM dengan 2,6 watt tegangan AC menjadi 1,1 tegangan dc ke sebuah beban dengan kecepatan rotor $120 \mathrm{krpm}$ menggunakan magnet permanent SmCo berdiameter 9,5 mm [10-11].

Telah banyak dilakukan study kasus tentang pengaruh effek dari bentuk magnet permanen pada karakteristik torque ripple dari mesin [12-14]. Pada penelitian ini, akan dilakukan analisa simulasi dan eksperimen mengenai pengaruh dari bentuk geometri dan remanensi magnet $\mathrm{NdFeB}$ terhadap tegangan maksimum dari generator. Simulasi yang dilakukan menggunakan $3 D$ studio Max dan Visual basic net express software. Variasi bentuk magnet adalah circular dan rectangular. Pemilihan generator tipe ini memiliki torsi beban yang kecil dan biasanya digunakan untuk pembangkit listrik tenaga angin dan tidak menutup kemungkinan untuk pembangkit energi primer lainnya. Variasi kecepatan rotor sebesar 260-540 rpm dan densitas flux magnetik sebesar 0,5-1,3 Tesla.

\section{METODOLOGI}

Berdasarkan data dan spesifikasi generator yang dibuat, dapat diketahui nilai kerapatan fluks magnet maksimum, $\mathrm{B}_{\max }$, fluks maximum, $\phi$ maks, frekuensi, $f$ dan output tegangan induksi, Erms. Tampilan pengolahan data hasil simulasi generator axial flux permanent magnet dengan menggunakan perangkat lunak visual basic net express, diperlihatkan seperti pada Gambar 1.

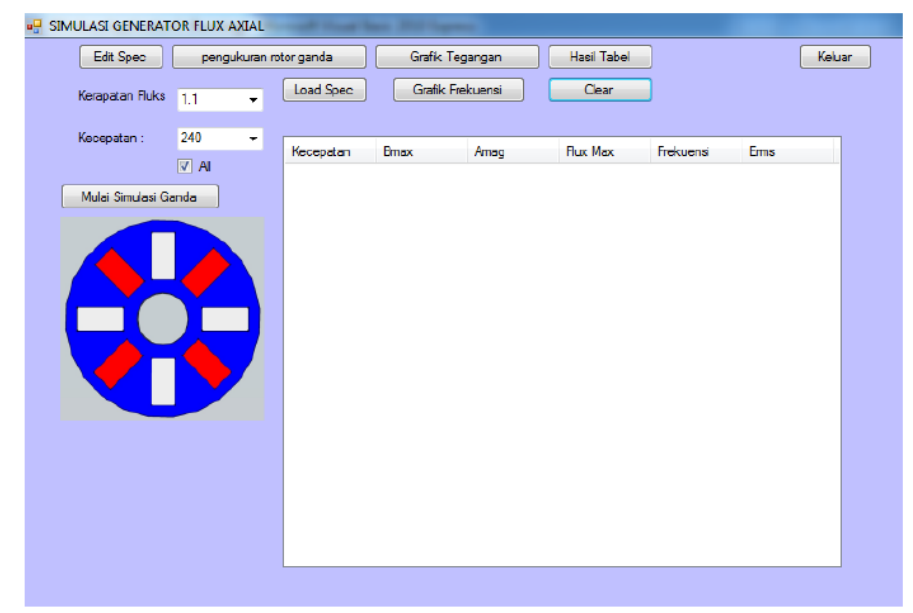

Gambar 1. Model Simulasi generator menggunakan 3D studio Max dan Visual basic net express software.

Dalam ekperimen, pembuatan generator dilakukan dengan kontruksi pada Gambar 2. Desain pemodelan generator ini terdiri dari tiga bagian utama, yakni rotor, stator dan celah udara. Pada generator ini digunakan magnet permanen $\mathrm{NdFeB}$ dengan kerapatan fluks magnet masing-masing 0,5 dan 1,1 Tesla untuk bentuk circular dan rectanguler Pemasangan magnet permanen dengan menggunakan cara embedded dan diletakkan pada salah satu permukaan rotor yang menghadap ke arah stator.
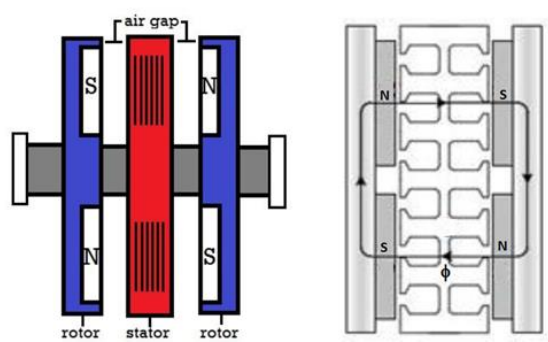

(a)

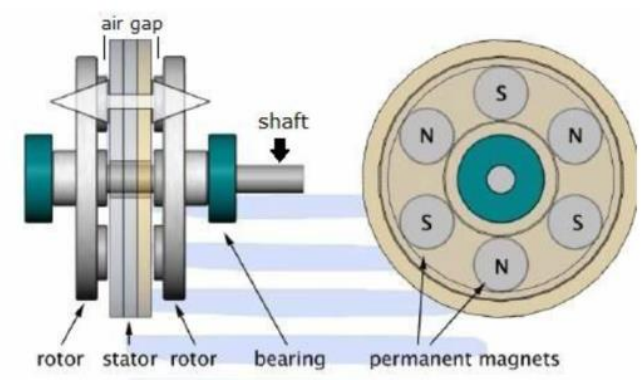

(b)

Gambar 2. Model kontruksi generator fluks aksial dengan geometri (a) circular [15] dan (b) rectangular [16]. 
Pemasangan magnet permanen ini dipilih agar tidak mudah lepas dan penyebaran fluks magnet merata. Posisi kutub magnet yang digunakan bertipe utara-selatan (NS) silih berganti terhadap magnet yang disebelahnya dan saling berhadapan dengan kutub magnet lainnya. Pada penelitian ini akan diuji generator yang telah dirakit, kemudian dibandingkan dengan hasil simulasi agar dapat diketahui sejauh mana korelasinya terhadap output tegangan induksi, $\mathrm{E}_{r m s}$. Beberapa variasi nilai kecepatan putar dan kerapatan fluks magnet juga digunakan untuk perhitungan simulasi untuk mendapatkan output tegangan induksi, Erms.

$$
E_{r m s}=\frac{2 \pi}{\sqrt{2}} N . f \emptyset_{\max }\left(\frac{N s}{N_{P H}}\right)
$$

Tabel 1. Data spesifikasi dari rotor dan stator pada generator.

\begin{tabular}{|c|c|c|c|c|}
\hline \multirow{2}{*}{\multicolumn{2}{|c|}{ Parameter }} & \multirow{2}{*}{ Lambang } & \multicolumn{2}{|c|}{ Bentuk magnet } \\
\hline & & & Circular & Rectangular \\
\hline \multicolumn{5}{|c|}{ A. Rotor } \\
\hline o & Kerapatan fluks magnet & $\mathrm{Br}$ (Tesla) & 0,5 & 1,1 \\
\hline o & Dimensi magnet & $(\mathrm{mm})$ & & $P=40$ \\
\hline o & & & $\Phi=50$ & $\mathrm{~L}=17$ \\
\hline o & & & & $\mathrm{t}=\mathrm{l}_{\mathrm{m}}=5$ \\
\hline o & Jumlah magnet & $\mathrm{N}_{\mathrm{m}}$ (buah) & 8 & 8 \\
\hline ○ & Radius dalam magnet & $r_{i}(\mathrm{~mm})$ & 60 & 60 \\
\hline ○ & Radius luar magnet & $r_{o}(\mathrm{~mm})$ & 110 & 120 \\
\hline o & Jarak antar magnet & $\tau_{\mathrm{f}}(\mathrm{mm})$ & 35 & 30 \\
\hline o & Kecepatan putar & $\mathrm{N}(\mathrm{rpm})$ & variable & variable \\
\hline o & Jumlah kutub magnet & $\mathrm{P}$ (buah) & 8 & 8 \\
\hline \multicolumn{5}{|c|}{ B. Stator } \\
\hline o & Jumlah kumparan & $\mathrm{N}_{\mathrm{s}}(\mathrm{buah})$ & 6 & 6 \\
\hline ० & Jumlah lilitan & $\mathrm{N}$ (lilitan) & 400 & 400 \\
\hline o & Diameter Yoke & $\mathrm{D}_{\mathrm{s}}(\mathrm{mm})$ & 300 & 300 \\
\hline \multicolumn{2}{|c|}{ Jarak celah udara } & $\mathrm{Lg}(\mathrm{mm})$ & 25 & 25 \\
\hline \multicolumn{2}{|c|}{ Jumlah fasa } & $\mathrm{N}_{\mathrm{ph}}$ & 1 & 1 \\
\hline \multicolumn{2}{|c|}{ Luas penampang } & $\mathrm{A}\left(\mathrm{cm}^{2}\right)$ & 24 & 19.625 \\
\hline
\end{tabular}

\section{HASIL DAN PEMBAHASAN}

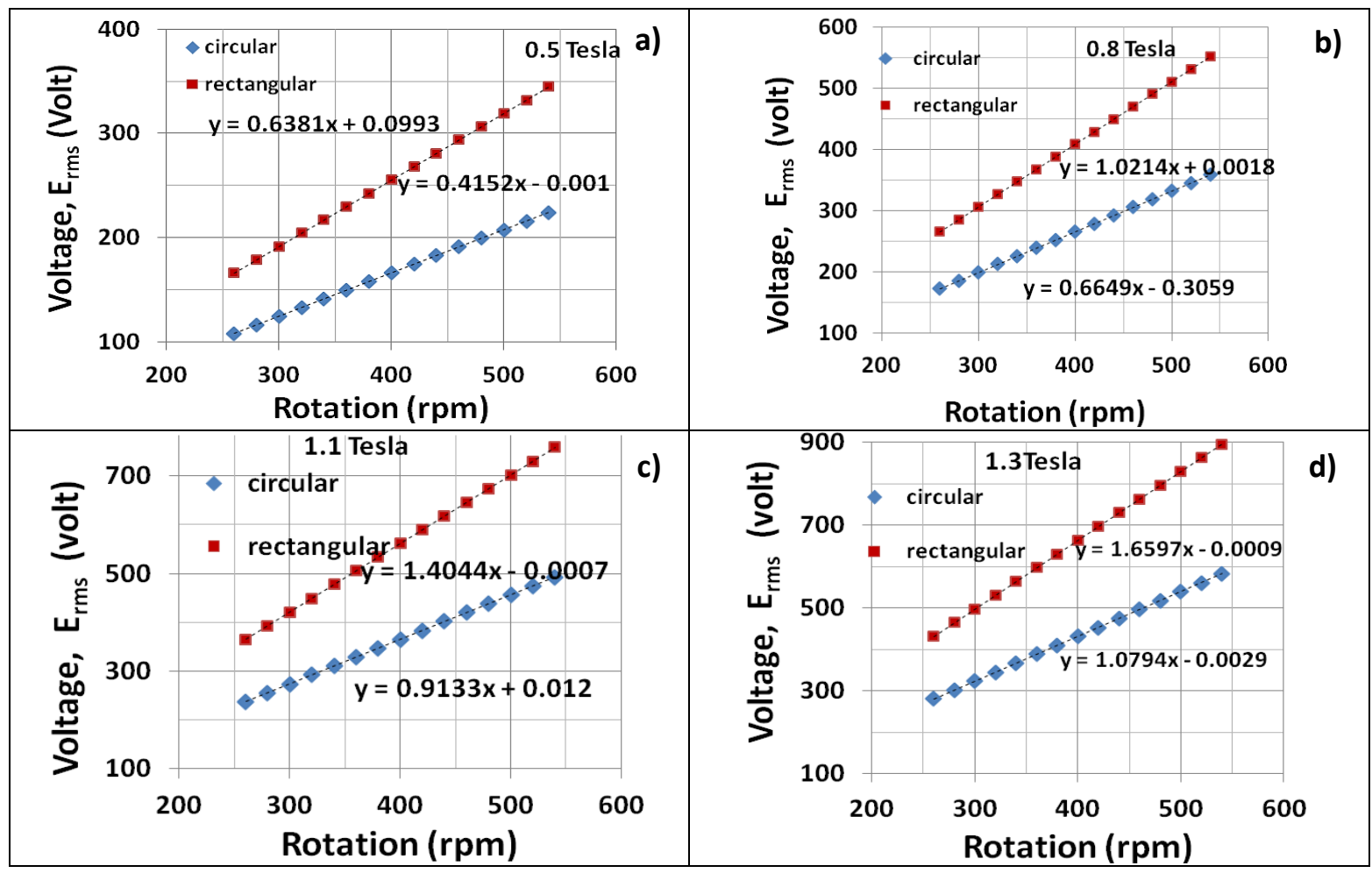

Gambar 3. Pengaruh rotasi rotor dan bentuk magnet terhadap tegangan generator dengan medan magnet (a) 0,5 Tesla, (b) 0,8 Tesla, (c) 1,1 Tesla, dan (d) 1,3 Tesla menggunakan simulasi. 
Pada Gambar 3, Dari hasil simulasi diperlihatkan hubungan voltage, $\mathrm{E}_{\mathrm{rms}}$ terhadap kecepatan putar (rotasi) untuk bentuk magnet permanen circular dan rectangular masing-masing dengan magnetic flux density sebesar 0,5; 0,8; 1,1; dan 1,3 Tesla. Dari Gambar 3(a), pada magnetic flux density sebesar 0,5 Tesla, maka voltage yang dihasilkan, $\mathrm{E}_{\mathrm{rms}}$ dari magnet circular adalah $\mathrm{E}_{\mathrm{rms}}=0,4152 \mathrm{X}-0,001$ dan rectangular $\mathrm{E}_{\mathrm{rms}}=0,64 \mathrm{X}-0,1$, dimana $\mathrm{X}$ $=$ rotation $(\mathrm{rpm})$. Dari hasil ini menunjukkan bahwa output generator menggunakan magnet permanen bentuk rectangular relatif lebih tinggi dibandingkan bentuk circular, hal ini disebabkan oleh luas penampang magnet yang lebih besar.

Magnetik flux density sangatlah berpengaruh terhadap output tegangan, $\mathrm{E}_{\mathrm{rms}}$ jika magnetik flux density semakin besar maka output tegangan juga bertambah besar, artinya ada hubungan berbanding lurus dengan kecepatan putar yang tetap. Output tegangan $\mathrm{E}_{\mathrm{rms}}$ pada magnetik flux density 0,8 $\mathrm{T}$ masing-masing untuk bentuk circular dan rectangular memenuhi persamaan: $\mathrm{E}_{\mathrm{rms}}=0,665 \mathrm{X}-0,306$ dan $\mathrm{E}_{\mathrm{rms}}=1,0214 \mathrm{X}-0,002$. Pada saat magnetic flux density dinaikkan menjadi $1,1 \mathrm{~T}$ maka $\mathrm{E}_{\mathrm{rms}}$ dari masing-masing bentuk circular dan rectangular adalah $\mathrm{E}_{\mathrm{rms}}=0,913 \mathrm{X}+0,012$ dan $\mathrm{E}_{\mathrm{rms}}=1,4044 \mathrm{X}-0,0007$.

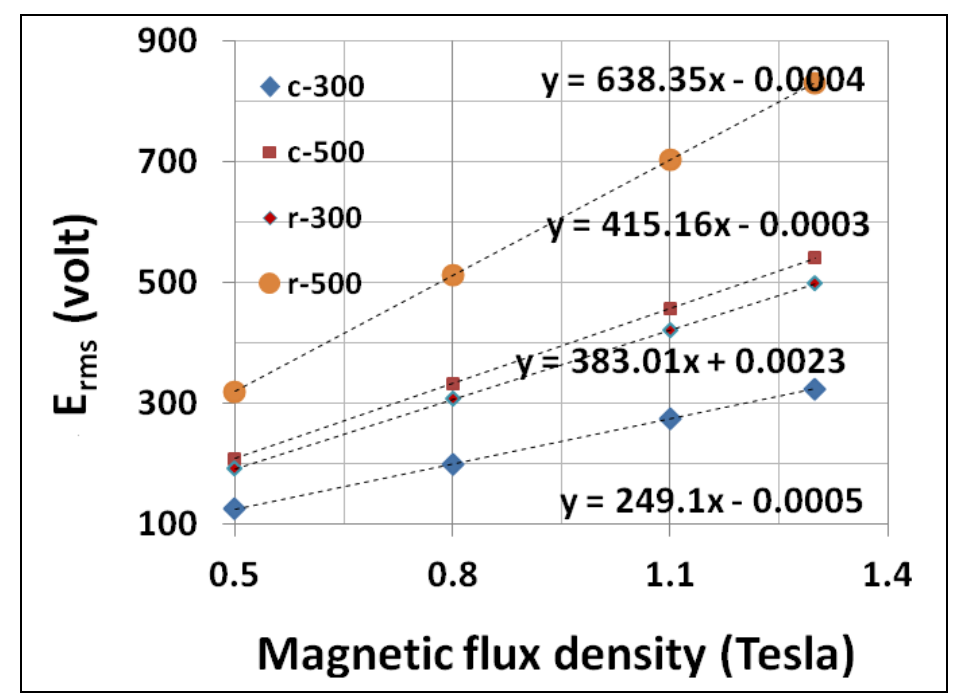

Gambar 4. Pengaruh magnetic flux density dan bentuk magnet terhadap tegangan generator dengan rotasi rotor 300 dan $500 \mathrm{rpm}$.

Hasil simulasi juga menunjukkan adanya pengaruh yang sangat signifikan dari rotasi rotor terhadap output tegangan yang dihasilkan generator. Pada Gambar 3, diketahui bahwa semakin besar rotasi pada rotor maka berbanding lurus dengan hasil tegangan pada generator. Besarnya tegangan yang dibangkitkan tergantung pada kecepatan garis medan magnet yang dipotong atau dalam hal generator $\mathrm{AC}$, besarnya tegangan tergantung pada kuat medan dan kecepatan rotor. Dari hubungan di atas terlihat bahwa bentuk dan ukuran magnet permanen sangat mempengaruhi besarnya magnetic flux density yang digunakan. sangat mempengaruhi output tegangan induksi $\mathrm{E}_{\mathrm{rms}}$ Yang dihasilkan. Penyebaran luas penampang magnetik flux density terhadap output generator AFPM sesuai dengan rumusan tegangan induksi, $\mathrm{E}_{r m s}=\left[\left(2 \pi \sqrt{ } 2 . N . f . \emptyset_{\max }\right)\left(N_{s} / N_{p h}\right)\right]=4.44$ N.f. $\emptyset_{\max }\left(N_{s} / N_{p h}\right)$.

Hasil eksperimen juga menunjukkan korelasi yang sama diantara bentuk magnet (circular atau rectangurlar), magnetic flux density, dan kecepatan putar rotor (rotasi) sangat mempengaruhi output tegangan. Namun output tegangan pada hasil experimen lebih rendah dibandingkan hasil simulasi. Ini disebabkan terjadinya energy loss akibat celah udara (gap) yang tidak dapat di hitung dengan menggunakan simulasi.

\section{KESIMPULAN}

Pada penelitian ini telah dilakukan pembuatan generator axial flux magnetic menggunakan magnet $\mathrm{NdFeB}$ yang dibentuk circular dan rectangular. Pembuatan generator telah diuji dan dihitung secara simulasi menghasilkan pola yang sesuai, output tegangan, $E_{\mathrm{rms}}$ dan frekuensi, f memenuhi persamaan: $\mathrm{E}_{\mathrm{rms}}=1,41 \mathrm{X}-4,3$ dan $\mathrm{f}=0,07 \mathrm{X}+0,05$, dimana $\mathrm{X}$ adalah kecepatan putar rotor pada generator listrik. Semakin tinggi kecepatan putar rotor generator listrik maka output tegangan induksi, $\mathrm{E}_{\mathrm{rms}}$ dan frekuensi, $\mathrm{f}$ akan semakin besar, dan tingkat kesalahannya akan semakin kecil. Pada hasil eksperimen magnet permanent dengan bentuk circular, diputar dengan kecepatan konstan sebesar 500 rpm akan menghasilkan $\mathrm{E}_{\mathrm{rms}}=415,16 \varnothing-0,0003$. dan dibandingkan dengan 
rectangular menghasilkan, $\mathrm{E}_{\mathrm{rms}}=638,35 \varnothing-0,0004$, dimana $\emptyset=$ Magnetik flux density (Tesla). Artinya bentuk terutama luas penampang magnet, A $\left(\mathrm{cm}^{2}\right)$ dan kerapatan fluks magnet, $\emptyset$ sangat mempengaruhi output tegangan induksi, $\mathrm{E}_{\mathrm{rms}}$. Dengan demikian penyebaran luas penampang magnetic flux density terhadap output generator sesuai dengan rumusan tegangan induksi, $\mathrm{E}_{r m s}=\left[\left(2 \pi \sqrt{ } 2 . N . f . \emptyset_{\max }\right)\left(N_{s} / N_{p h}\right)\right]=4.44$ N.f. $\emptyset_{\max }\left(N_{s} / N_{p h}\right)$.

\section{DAFTAR PUSTAKA}

[1]. S. Meninger, J. O. Mur-Miranda, R. Amirtharajah, A. P. Chandrakasan, dan J. H. Lang, "Vibration-toelectric energy conversion," IEEE Trans. Very Large Scale Integr. (VLSI) Syst., vol. 9, no. 1, hal. 64-76, 2001.

[2]. C. B. Williams, C. Shearwood, M. A. Harradine, P. H. Mellor, T. S. Birch, dan R. B. Yates, "Development of an electromagnetic micro-generator," IEE Proc. Circuit Device Syst., vol. 148, no. 6, 2001.

[3]. J. M. H. Lee, S. C. L. Yuen, W. J. Li, dan P. H.W. Leong, "Development of an AA size transducer with micro resonators," Proc. ISCAS 2003, vol. 4, hal. 876-879, 2003.

[4]. P. Glynne-Jones, S. P. Beeby, dan N. M. White, "Toward a piezoelectric vibration-powered microgenerator," IEE Proc. Sci. Meas. Technol., vol. 148, no. 2, 2001.

[5]. H. Polinder, F.F.A. van der Pijl, G.J. de Vilder, dan P. Tavner, "Comparison of direct-drive and geared generator concepts for wind turbines," IEEE Trans. Energy Conversion, vol. 21, hal. 725-733, 2006.

[6]. J. F. Gieras, R. J. Wang, dan M. J. Kamper, Axial Flux Permanent Magnet Brushless Machines, 2nd ed., Springer, 2008.

[7]. M. Sadeghierad, A. Darabi, H. Lesani, dan H. Monsef, "Rotor yoke thickness of coreless high speed axialflux permanent magnet generator," IEEE Trans. Magn., vol. 45, no. 4, hal. 2032-2037, 2009.

[8]. W. Fei dan P. C. K. Luk, "Design and performance analysis of a high-speed air-cored axial-flux permanentmagnet generator with circular magnets and coils," Proc. IEEE int. Eletric Machines \& Drives conf., hal. $1-10,2009$.

[9]. A. S. Holmes, G. Hong, dan K. R. Pullen, "Axial-flux permanent magnet machines for micro power generation," J. Microelectromech. Syst., vol. 14, no. 1, hal. 54-62, 2005.

[10]. Das S, Arnold D P, Zana I, Park J-W, Allen M G dan Lang J H, "Microfabricated high-speed axial-flux multi-watt permanent-magnet generators: Part I. Modeling,” J. Microelectromech. Syst. (at press), 2006

[11]. Arnold D P, Das S, Zana I, Park J-W, Lang J H dan Allen M G, "Microfabricated high-speed axial-flux multi-watt permanent-magnet generators: Part II. Design, fabrication, and testing," J. Microelectromech. Syst. (at press), 2006.

[12]. W. Fei dan P. C.K. Luk, "Torque Ripple Reduction of a Direct-Drive Permanent-Magnet Synchronous Machine by Material-Efficient Axial Pole Pairing," IEEE Transaction on Industrial Electronics, vol. 59, no. 6, 2012.

[13]. N. N. Chen, S. L. Ho, dan W. N. Fu, "Optimization of permanent magnet surface shapes of electric motors for minimization of cogging torque using FEM," IEEE Trans. Magnetics, vol. 46, no. 6, hal. 2478-2481, 2010.

[14]. D. K. Woo, J. H. Choi, M. Ali, dan H. K. Jung, A Novel Multimodal Optimization Algorithm Applied to Electromagnetic

[15]. L. D. Ferraro, R. Terrigi, dan F. G. Capponi, "Coil and Magnet Shape Optimization of an Ironless AFPM Machine by Means of 3D FEA,” IEEE., 2007.

[16]. M. Aydin, S. Huang, dan T. A. Lipo, Torus Concept Machine: Pre-Prototyping Design Assesment for Two Major Topologies, University of Wisconsin-Madison College of Enginering. 2004. 